\title{
A eficiência de algoritmos matemáticos para avaliação do ruído urbano
}

\section{The efficiency of mathematical algorithms for urban noise evaluation}

Luiz Antonio Perrone Ferreira de Brito, João Batista Carvalho Junior, Vitória Dellamônica Toledo

Universidade de Taubaté (UNITAU), Taubaté, SP, Brasil

\section{Resumo}

A paisagem sonora das cidades, sejam de médio ou grande porte, em algumas situações específicas pode não ser favorável ao conforto da população e até mesmo para sua saúde. 0 tráfego de veículos é uma das principais causas dessa condição, fato agravado pelo descontrole da ocupação urbana, que vem eliminando recuos frontais, praças e jardins, que possibilitariam uma maior dispersão da energia sonora. 0 planejamento urbano requer ferramentas que lhe permitam estimar a emissão de energia sonora de vias de tráfego. No mercado existem softwares comerciais que fazem tal previsão, mas possuem um custo elevado. A opção é a utilização de algoritmos matemáticos disponíveis na literatura, sem custo, mas que foram desenvolvidos para uma realidade diferente da brasileira. 0 objetivo deste trabalho é avaliar a precisão desses algoritmos para a realidade brasileira. Para isso foram executadas medidas de nível de pressão sonora em uma via de tráfego. Durante as medições foi realizada a contagem do fluxo de veículos, para alimentar os algoritmos selecionados e assim comparar o valor medido e o simulado. 0 resultado indica que há uma boa correlação nos valores obtidos, mas o ruído emitido pelos veículos em circulação precisa ainda ser melhor estudado para se buscarem resultados mais precisos.

Palavras-chave: Ruído de tráfego. Planejamento urbano. Ruído urbano.

\section{Abstract}

The soundscape of cities in general, whether medium or large size, may not be favorable to the comfort of the population and even to the health of people. Vehicle traffic is one of the main causes of this problem, further worsened by uncontrolled urban growth which eliminates front setbacks, squares and gardens that could enable a better dispersion of sound energy. Urban planning requires tools that allow it to estimate sound energy emission from traffic flow. There are softwares in the market that make this prediction, but they have a high cost. The other option is the use of mathematical algorithms available cost-free in the literature, but that have been developed for a reality different from the Brazilian. The objective of this work is to evaluate the accuracy of these algorithms to the Brazilian reality. Sound pressure level measures were made in a traffic lane. During the

LAPFB é professor doutor do Programa de Pós-Graduação em Planejamento Urbano e Desenvolvimento Regional, e-mail: labrito@bighost.com.br

JBCJ é mestre do Programa de Pós-Graduação em Planejamento Urbano e Desenvolvimento Regional, e-mail: joaocabotex@gmail.com VDT é graduanda em Arquitetura e participante do Programa de Iniciação Científica, e-mail: vih_dt@hotmail.com 
measurements, the number of vehicles was counted to feed the selected algorithm in order to compare the measured and the simulated values. The results indicated a good correlation between the values obtained, but the noise emitted by vehicles in circulation need to be better studied in order to obtain more accurate results.

Keywords: Traffic noise. Urban planning. Urban noise.

\section{Introdução}

A Organização Mundial da Saúde (WHO, 2009) publicou recomendações sobre o excesso de ruído, alertando para problemas na saúde e bem-estar da população, que pode ser afetada por doenças a ele relacionadas, como stress, distúrbio no sono, irritabilidade e dificuldade na comunicação, por exemplo. A OMS considera o ruído como o segundo maior poluidor ambiental, atrás apenas da poluição das águas. Segundo Ivanovic et al. (2014), estima-se que cerca de 50 milhões de pessoas na União Europeia estão expostas a níveis de ruído acima do indicado pela Organização Mundial da Saúde. Weber et al. (2014) apresentaram um estudo relacionando o stress induzido pelo ruído na população e sua influência no sistema imunológico humano. Concluíram que pode haver doenças respiratórias relacionadas e essa situação. Um agravante dessa situação é a demora do aparecimento dos primeiros sintomas das doenças mais graves causadas pelo excesso de ruído, dificultando ou até mesmo impossibilitando o tratamento. Belojević et al. (2008) relataram aumento da hipertensão arterial masculina devido a elevado nível de ruído gerado pelo tráfego de veículos, Pirrera et al. (2014) concluíram que a principal causa de distúrbios do sono na Bélgica também relaciona-se a ruído gerado pelo tráfego de veículos.

As reclamações encaminhadas aos órgãos públicos em Taiwan devidas ao excesso de ruído correspondem quase a $70 \%$ do total recebido, sendo que $90 \%$ da população é exposta a um nível de ruído acima do aceitável segundo estudo realizado por Tsai et al. (2009). 0 excesso de ruído também pode prejudicar atividades econômicas como o turismo, conforme demostrado por Brito \& Barbosa (2014). Os autores, por meio de mapeamento de ruído ambiental, demonstraram a situação conflitante nas cidades de pequeno porte que possuem o turismo como a principal atividade econômica. 0 problema está na diferença entre os interesses dos turistas que procuram o lazer e os que procuram o descanso, sendo esses prejudicados pelo ruído gerado pelos demais. Há também nessa situação o incômodo que as atividades de entretenimento ligadas ao turismo geram na população local, acostumada à tranquilidade das cidades pequenas. Essa situação é agravada pela ausência de planejamento urbano que não distingue zonas residenciais das de entretenimento. Na Europa, por exemplo, estimam-se perdas na atividade econômica de turismo de $€ 13$ a $€ 38$ milhões, no ano de 2001, devido ao incômodo gerado pelo ruído, segundo estudo apresentado por Estévez et al. (2013).

Outro efeito pernicioso do excesso de ruído no meio urbano é a influência no preço das edificações devido à preferência por locais mais silenciosos. Segundo estudo de Łowicki \& Piotrowska (2015), há um decréscimo médio no preço das edificações na Polônia de cerca de $2,9 \%$ por $\mathrm{dB}(\mathrm{A})$ de acréscimo no critério de ruído normalizado, decréscimo esse de $3,0 \%$ na Suécia e de 1,3\% na Coréia do Sul. Segundo os autores, o decréscimo no preço é mais significativo nas periferias das cidades, afetando principalmente a população de menor renda. Segundo Szczepanska et al. (2015), o planejamento urbano nas cidades europeias precisa considerar com mais ênfase a poluição sonora pois, com o passar dos anos, o excesso de ruído afeta o custo médio das edificações, gerando prejuízo financeiro e afetando a saúde da população. No Brasil ainda não há uma pesquisa conclusiva sobre esse tema.

0 processo de licenciamento ambiental pode auxiliar os gestores públicos no planejamento urbano, pois possibilita a antevisão dos futuros impactos de um empreendimento com potencial para gerar efeitos negativos à população, de diversas formas, entre elas a geração e propagação de ruído. Para tal são necessárias ferramentas matemáticas que possibilitem a predição futura do ruído gerado por uma via de tráfego, de maneira que possa ser confrontada com a normalização. No mercado é possível obter softwares comerciais que atendem a essa função, mas com um custo elevadíssimo, cotado em moeda estrangeira. Outra forma de previsão de geração do ruído de tráfego são algoritmos matemáticos disponíveis na literatura, capazes de tais previsões, abertos para 
serem utilizados sem custo. Esses são desenvolvidos em outros países, com realidades diferentes da do Brasil, seja no tipo e conservação do pavimento, no tipo e conservação dos veículos ou maneira de dirigir. Dessa forma é necessário saber qual desses algoritmos melhor se adapta a realidade brasileira.

0 objetivo deste trabalho foi avaliar quais algoritmos matemáticos melhor se adaptam à realidade de vias, veículos e modo de dirigir brasileiros.

\section{Revisão da literatura}

A principal fonte de ruído na escala urbana é o tráfego de veículos, principalmente nas zonas lindeiras às grandes artérias de circulação nas cidades (Zhao et al., 2015). Esta situação pode ser encontrada em capitais e cidades de grande porte (Niemeyer \& Cortês, 2012) ou mesmo em cidades de médio porte (Giunta et al., 2012) e de pequeno porte (Scherer et al., 2008). Szeremeta \& Zannin (2009) concluíram que o tráfego de veículos no entorno dos parques de Curitiba é a segunda fonte de ruído mais notada pelos usuários, sendo considerado desagradável pela maioria dos entrevistados. Segundo Schimitt (2014), que apresentou um estudo com o mapeamento de ruído na cidade de Porto Alegre, a normalização que limita o nível de ruído no meio urbano não é atendida em praticamente toda nenhuma região da cidade, Aleixo et al. (2014) chegaram à mesma conclusão em Goiânia e Guedes et al. (2014), na cidade de Aracaju. Klæboe et al. (2004) concluíram que o critério de $55 \mathrm{~dB}(\mathrm{~A})$, adotado pela Comunidade Europeia como padrão para áreas habitadas tem um potencial de incômodo em $40 \%$ dos 4 mil entrevistados na Noruega. Cerca de $12 \%$ dos entrevistados sentem-se altamente incomodados, 28\%, incomodados, 35\% escutam mas não se incomodam e $25 \%$ não escutam o ruído gerado no meio urbano. Considere-se nessa situação a diferença da tipologia construtiva europeia, em que a necessidade de isolamento térmico resulta em um bom isolamento acústico, e a brasileira, na qual a ventilação é prioridade devido ao clima, o que mantém as janelas abertas, facilitando a difusão de ruídos intrusivos.

A norma brasileira que regula a avaliação do ruído gerado em ambientes urbanos é a NBR 10151 - Avaliação de ruídos em áreas habitadas visando o conforto da comunidade, a qual está em processo de revisão no momento (ABNT, 2000). A NBR 10151 (2000) indica o Nível Critério de Avaliação (NCA) para os períodos diurno e noturno conforme o tipo de ocupação no local. Por exemplo, para áreas de ocupação mista, em geral lindeiras às vias de tráfego de maior capacidade, o NCA é de $55 \mathrm{~dB}(\mathrm{~A})$ e $50 \mathrm{~dB}(\mathrm{~A})$ para os períodos diurno e noturno, respectivamente. Brito (2009) apresentou uma relação de estudos realizados no Brasil onde o ruído gerado pelo tráfego de veículos supera com folgada margem esses parâmetros, tornando-se uma das principais causas de desconforto no meio urbano. Na Comunidade Europeia o critério utilizado é o Nível Dia e Noite, $\mathrm{L}_{\mathrm{dn}}$. $0 \mathrm{~L}_{\mathrm{dn}}$ é composto por outros dois índices o $\mathrm{L}_{\mathrm{d}^{\prime}}$ que é o nível de ruído dia, medido entre 7 e 22 horas, e o $\mathrm{L}_{\mathrm{n}}$, que é o nível de ruído noite, medido entre 22 e 7 horas, esse acrescido de $10 \mathrm{~dB}(\mathrm{~A}) .0$ valor de $\mathrm{L}_{\mathrm{dn}}$ para áreas habitadas é de $55 \mathrm{~dB}(\mathrm{~A})$ (Klæboe et al., 2004). Considerando o $\mathrm{L}_{\mathrm{d}}$ de $55 \mathrm{~dB}(\mathrm{~A})$, como a NBR 10151 (2000) indica para o período diurno, o $\mathrm{L}_{\mathrm{n}}$ deve ser de $45 \mathrm{~dB}(\mathrm{~A})$ para que o índice $L_{d n}$ de $55 \mathrm{~dB}(\mathrm{~A})$ seja atendido, ou seja $5 \mathrm{~dB}(\mathrm{~A})$ menor que o considerado no Brasil para o período noturno. Segundo pesquisas de Musafir (2008), o NCA da NBR 10151 (2000) é continuamente desrespeitado, em geral, pelo ruído gerado pelo tráfego de veículos. Essa situação expõe a população em geral a níveis de ruído acima do normalizado, fato ainda agravado pelo fato de a normalização brasileira impor critérios inferiores aos europeus.

Segundo Ivanovic et al. (2014) uma das principais ferramentas para o controle da dispersão do ruído pelas cidades é o planejamento urbano. Esse envolve variáveis complexas, como o tráfego de veículos leves e pesados, relacionado com a poluição sonora e do ar, mas necessário para a mobilidade urbana. A morfologia das cidades, como, por exemplo, posicionamento de edifícios nas quadras, sua altura, recuos frontais e laterais, além da taxa de ocupação de lotes, é significativa nesse processo, podendo reduzir em até $6 \mathrm{~dB}(\mathrm{~A})$ o nível de ruído em uma região, segundo Silva et al. (2014). Outros autores, como Weber et al. (2014) e Ariza-Villaverde et al. (2014), chegaram a conclusões semelhantes em seus estudos. Szeremeta \& Zannin (2009) concluíram que fatores como zoneamento urbano, tipo de vias de circulação, vegetação e tipo de transporte público são influentes nas características sonoras de parques públicos. A densidade populacional e de veículos são fatores que também influenciam a paisagem sonora de uma cidade, segundo estudos de 
Salomons \& Pont (2012) nas cidades de Rotterdam e Amsterdam. De acordo com os autores, há uma ligação direta entre esses dois fatores e a quantidade de reclamações devidas ao excesso de ruído nos órgãos municipais. Concluíram também que a alta densidade populacional influi na forma do posicionamento dos edifícios nas quadras, alinhados, alternados ou aleatórios, de forma que podem propiciar ou não a dispersão da energia sonora. Por exemplo, no caso do posicionamento dos edifícios alinhados nas quadras são criados "corredores acústicos" nos quais há uma forte tendência de propagação da energia sonora, sendo criadas, assim, regiões de maior ou menor nível de ruído. Essa tipologia de ocupação pode ser utilizada como parâmetro de projeto urbano, no qual áreas comerciais podem ocupar tais "corredores" e as residências, ficar afastadas. Já a tipologia alternada ou aleatória dificulta a dispersão da energia sonora mas, ao mesmo tempo, não a concentra em certos pontos, tornando a paisagem sonora semelhante em toda uma região, sendo indicada para áreas apenas de ocupação residencial.

A engenharia acústica permite a ação diretamente no receptor, no meio de propagação ou na fonte de ruído para reduzir os impactos em geral. No caso da intervenção no receptor, a ação projetual visa o aumento do isolamento acústico das fachadas, paredes e janelas, que é prejudicada pela tipologia climática predominante em praticamente todo o território nacional, no qual a ventilação é primordial para o conforto térmico, principalmente em áreas mais úmidas. No caso das janelas permanecerem fechadas, há necessidade de refrigeração. Deve-se considerar também que ao se adotar esse partido o meio urbano é relegado à deterioração, de maneira que se protege o receptor em sua residência ou local de trabalho, mas o mesmo fica exposto quando transita nos ambientes externos. As intervenções urbanas possíveis no meio de propagação da energia sonora são a vegetação rasteira, de médio e de grande porte, e as barreiras acústicas naturais, geradas pelas diferenças topográficas e taludes. A implantação de praças, jardins e taludes vegetados precisa fazer parte do projeto urbano, não podendo ser utilizada de maneira corretiva, apenas preventiva. Outra forma de atenuação da energia sonora é o aumento da distância entre a fonte de ruído e o receptor. A redução dos recuos das edificações em relação às vias de tráfego, gerada especialmente pela especulação imobiliária, dificulta e dispersão da energia sonora além de aproximar a fonte de ruído do receptor. Outros efeitos ambientais também podem ser observados devido à proximidade das edificações, como a formação das ilhas de calor, resultante do acúmulo da radiação solar nos corpos sólidos durante o dia, que não é emitida ao céu durante a noite, a redução da ventilação e a exposição da população a vibração gerada pelo tráfego de veículos (Brito, 2014). 0 adensamento urbano também favorece as reflexões sonoras, ou seja, ao invés de dispersar as ondas sonoras, as fachadas dos edifícios as refletem de volta, concentrando-as e elevando o nível de ruído no local. As barreiras artificiais, como muros de concreto ou alvenaria, podem também ser utilizadas como ferramentas de projeto urbano para controle da poluição sonora, mas possuem limitações, como a redução da mobilidade de pedestres, redução da ventilação, em alguns casos, o sombreamento das edificações, além de possibilitarem acidentes. Dessa forma, essas intervenções são recomendadas somente em casos específicos, como em rodovias, nas quais há espaço para sua construção. Ou seja, as intervenções no meio de propagação não são possíveis ou são raras de se conseguir se não fizerem parte do planejamento urbano e forem implantadas antes da consolidação da ocupação. Já a intervenção na fonte de ruído, essa é a mais desejada, pois beneficia todo o espaço urbano, pode ser feita diretamente nos veículos, no pavimento de rodagem e na forma como o tráfego é organizado. Segundo Eisenblaetter et al. (2010), a indústria automobilística já reduziu ao máximo o ruído gerado pela suspenção e sistema motor-transmissão dos veículos, restando apenas a necessidade de fiscalização pública para que as condições originais dos veículos sejam mantidas. 0 tipo de pavimento asfáltico influi na emissão de energia sonora ao meio ambiente (Fehrl, 2006). Os pavimentos porosos, não confundir com rugosos, facilitam o escoamento da água, dificultando a aquaplanagem, e diminuem o spray do tráfego, melhorando a visibilidade. 0 principal emissor de ruído em veículos leves, acima de $60 \mathrm{~km} / \mathrm{h}$, é o efeito aerodinâmico causado pela passagem do fluxo de ar pelos sulcos dos pneus (Heckl, 1985). 0 fluxo de ar é comprimido contra a camada superior do pavimento pelo movimento de rotação do pneu, produzindo o chamado efeito corneta. $\mathrm{O}$ pavimento poroso aberto facilita a passagem do fluxo de ar, o que resulta em uma menor emissão de energia sonora, o que não ocorre no pavimento totalmente liso e fechado. 0 pavimento poroso possui também o efeito benéfico da absorção 
sonora, que reduz a propagação da onda acústica pelo meio urbano (Golebiewski etal., 2003). Brito (2014), em sua pesquisa sobre o ruído gerado por vários tipos de pavimento, concluiu que os asfaltos porosos tipo Stone Matrix Asphalt (SMA) com graduação 0/8 e 0/11 podem reduzir a emissão de energia sonora em até $5 \mathrm{~dB}(\mathrm{~A})$ em relação ao Concreto Asfáltico Denso (CA), que é o mais utilizado no Brasil. Paje et al. (2010) concluíram também que a adição de flocos de borracha como agregado na massa asfáltica possibilita ainda uma redução de mais $2 \mathrm{~dB}(\mathrm{~A})$. 0 estado de conservação do pavimento também deve ser considerado, já que os impactos da suspensão dos veículos é uma fonte importante de emissão de energia sonora e vibratória. A organização do tráfego de veículos no meio urbano também contribui para a redução na poluição sonora. Uma das formas desse controle é a velocidade dos veículos, já que a partir de $60 \mathrm{~km} / \mathrm{h}$ h o ruído gerado pelos pneus dos veículos leves predomina sobre o ruído gerado pelo conjunto motor-transmissão (Heckl, 1985), ou seja, a redução da velocidade pode também reduzir a emissão de energia sonora, em que pese seus efeitos na mobilidade urbana. Segundo os estudos apresentados pelo Fórum Europeu de Estudo de Rodovias (Fehrl, 2006), a redução da velocidade de $50 \mathrm{~km} / \mathrm{h}$ para $30 \mathrm{~km} / \mathrm{h}$ diminui em $2 \mathrm{~dB}(\mathrm{~A})$ o nível de ruído, em média. 0 fluxo de tráfego constante, sem paradas em semáforos e cruzamentos, reduz a frenagem e aceleração dos veículos, podendo resultar em uma redução de até $4 \mathrm{~dB}(\mathrm{~A})$, principalmente em locais onde o tráfego de veículos pesados predomina. A sinalização de solo pode elevar a emissão de energia sonora em até $6 \mathrm{~dB}(\mathrm{~A})$, no caso de possuir ângulos retos, ou em apenas $2 \mathrm{~dB}(\mathrm{~A})$, caso possua ângulos arredondados.

As ferramentas matemáticas de predição de propagação do nível de ruído em uma via de tráfego podem ser divididas em dois diferentes grupos. O primeiro grupo, mais tradicional e antigo, utiliza o ruído máximo $\left(\mathrm{L}_{\max }\right)$ gerado pela passagem de cada tipo de veículo, leve, médio, pesado, motocicletas, como base para o cálculo da energia sonora média $\left(\mathrm{L}_{\mathrm{Aeq}}\right)$, em geral para o período de uma hora. Nessa abordagem a fonte é considerada monopolo, ou seja, considera-se apenas o ruído gerado pelo motor. 0 outro grupo de algoritmos utiliza o nível de ruído médio em um dado período de tempo, $10 \mathrm{~s}\left(\mathrm{~L}_{10 \mathrm{~s}}\right)$ e $20 \mathrm{~s}\left(\mathrm{~L}_{20 \mathrm{~s}}\right)$ e assim por diante, gerado pela passagem de cada tipo de veículo. Nessa, a fonte é considerada dipolo, nela, além do motor, é possível captar o ruído gerado por outras partes do veículo (Pamanikabud et al., 2008).

Dentro do grupo que considera a fonte como monopolo, ou seja, um ponto único emissor de ruído em movimento contínuo, está o modelo proposto pela Federal Highway Administration (Steele, 2001). Esse calcula o nível de pressão sonora equivalente $\left(\mathrm{L}_{\text {Aeq(1h) }}\right)$ para um período de uma hora, para um observador a $15 \mathrm{~m}$ do eixo central da via, baseado no nível de ruído máximo $\left(\mathrm{L}_{\text {max }}\right)$ obtido durante a passagem de uma dada categoria de veículo pelo período de $5 \mathrm{~s}\left(\mathrm{~L}_{5 \mathrm{~s}}\right)$, Equação 1, sendo $n$ o número de veículos que transitam por hora, $v / h$, para a categoria de veículo considerada, $v$ a velocidade $\mathrm{em} \mathrm{km} / \mathrm{h}$ do veículo, $d$ a distância entre o ponto de análise e o centro da via, $t$ o tempo de análise, em geral uma hora, e $\alpha$ o coeficiente que considera o tipo de solo, sendo $\alpha=0$ solo macio, como gramado, e $\alpha=1$ solo duro, como o concreto. As equações para o cálculo do $L_{5 \mathrm{~s}}$ em função da categoria do veículo, automóveis, caminhões e assim por diante, e de sua velocidade podem ser obtidas em FHWA (1998). $0 \mathrm{~L}_{\text {Aeq(1h,i) }}$ deve ser calculado para cada categoria, automóveis e caminhões, por exemplo, ( $L_{5 s, z}$ para $z$ categorias) e todos os resultados devem ser somados na forma logarítmica por meio da Equação 2.

$$
\begin{aligned}
& L_{\text {Aeq }(1 h, i)}=L_{5 s, z}+10 \log \left(\frac{n}{v^{*} t}\right)+10 \log \left(\frac{15}{d}\right)^{(1+\alpha)}-13 \\
& L_{\text {Aeq }(\text { Total })}=\sum_{i=1}^{z} 10 * \log \left(10^{\left(\frac{\text { LAeq }, i}{10}\right)}\right)
\end{aligned}
$$

0 algoritmo proposto pela FHWA, a partir dos anos 2000, foi atualizado e recebeu o nome comercial de STAMINA, tornando-se um modelo fechado, no qual não é possível o acesso a formulação (Steele, 2001), de maneira que suas atualizações não se adaptam à proposta desse trabalho.

O Her Majesty's Stationery Office (HMSO, 1988), do Departamento de Transportes do Reino Unido apresentou também um algoritmo para simulação do ruído de tráfego, Equação 3, sendo $p$ a quantidade de veículos pesados em relação aos leves (\%). 0 nível de pressão sonora é obtido para uma distância de 13,5 metros da lateral da via. Como a Equação 3 fornece o nível estatístico $L_{10}$ (no qual apenas $10 \%$ das medidas instantâneas obtidas no período de integração superam 
esse valor) deve-se, através da Equação 4, obter o $\mathrm{L}_{\text {Aeq(1h)' }}$ conforme proposto por Alexandre \& Barde (1975).

$$
\begin{aligned}
& L_{10}=10 * \log n+33 * \log \left(v+40+\frac{500}{v}\right)+10 \log \left(1+\frac{5 * p}{v}\right)-26,6 \\
& L_{\text {Aeq }(1 h)}=L_{10}-3
\end{aligned}
$$

O algoritmo representado pela Equação 3 foi adaptado por Lam \& Tam (1998) do original da HMSO (1988) conforme apresentado na Equação 5. Esses também sugerem uma correção de $-1 \mathrm{~dB}(\mathrm{~A})$ em caso de pavimento asfáltico betuminoso, como normalmente utilizado no Brasil. Para o cálculo do $\mathrm{L}_{\text {Aeq(1h) }}$ utiliza-se também a Equação 4.

$L_{10}=10,5 * \log n+34,8 * \log \left(v+40+\frac{500}{v}\right)+10,5 \log \left(1+\frac{5 * p}{v}\right)-34,4$

Tang \& Tong (2004) propuseram uma série de algoritmos baseados na formulação proposta por HMSO (1988) para obtenção não somente do índice estatístico $\mathrm{L}_{10}$ mas também outros, como o $\mathrm{L}_{90}$ e o $\mathrm{L}_{\text {Aeq }}$. Incluíram também no algoritmo a parcela que permite a consideração do gradiente em aclive, em que há maior esforço do motor e, por consequência, maior emissão de ruído. 0 algoritmo que permite o cálculo diretamente do $\mathrm{L}_{\text {Aeq(1h) }}$, sem necessidade do auxílio da Equação 4, é dado pelo Equação 6. Nessa equação não está considerado o termo referente ao gradiente da via, que pode ser obtido diretamente no texto dos autores.

$L_{\text {Aeq }(1 \mathrm{~h})}=10 * \log n+41,8 * \log \left(v+40+\frac{500}{v}\right)+10 \log \left(1+\frac{5 * p}{v}\right)-50,5(6)$

Tansatcha et al. (2005) propuseram um modelo matemático baseado não no $\mathrm{L}_{\max }$, obtido em um período de $5 \mathrm{~s}$, gerado por uma dada categoria de veículos, mas no $\mathrm{L}_{\text {Aeq }}$ em um período de $10 \mathrm{~s}$. Essa nova proposta permite um maior tempo de captação do ruído gerado pela passagem da fonte. 0 valor obtido em medições de campo do $\mathrm{L}_{5 \mathrm{~s}}$, como o utilizado no modelo original da FHWA (1998), pode não ser preciso devido a dificuldade de acionar o medidor de ruído exatamente 2,5 s antes da passagem do veículo, ou seja, apesar de o final da medição ser facilmente determinado (2,5 s após a passagem do veículo defronte ao medidor), o início não é. Outro fator determinante de erro nessa metodologia são os veículos longos e lentos, que demoram mais de $5 \mathrm{~s}$ para passar defronte ao medidor. Outra alteração no algoritmo foi sua formulação inicial, na qual foi considerada uma fonte dipolo, com irradiação da energia sonora em mais de uma direção. 0 nível de pressão sonora equivalente para um período de 1 hora é dado pela Equação 7.

$L_{\text {Aeq }(1 h, i)}=L_{10 s, i}+10 \log \left(\frac{15}{d}\right)^{\beta_{e f}}+10 \log n_{i}-25,563$

0 cálculo do Leq10s, i é feito por equações baseadas na categoria e velocidade de cada veículo, as quais podem ser obtidas em Tansatcha et al. (2005). 0 coeficiente $\beta_{e \rho}$ Equação 7, é obtido pela Equação 8 e representa o efeito da absorção das ondas sonoras devido à rigidez do solo, sendo que para os solos macios $\beta_{\text {macio }}=0,5$ e, para rígidos, $\beta_{\text {rígido }}=0$ e $\% \beta_{\text {macio }}$ a porcentagem de solo macio existente entre a via e o receptor. Para se obter o $L_{\text {Aeq(1h) }}$ utiliza-se a Equação 2.

$\beta_{\text {ef }}=\frac{\% \beta_{\text {macio }} * 0,5}{100}$

Ainda assim houve o questionamento por parte de alguns pesquisadores na obtenção do $L_{10 s^{\prime}}$ pelos mesmos motivos já citados, de modo que o período de medição passou para 20 s. Com isso se objetivou uma melhor amostra dos veículos longos, além de reduzir o erro no tempo de medição. Pamanikabud et al. (2008) propuseram a Equação 9 para o cálculo do $\mathrm{L}_{\text {Aeq(1h,i) }}$, na qual também se obtêm as equações que permitem o cálculo do $\mathrm{L}_{20, \mathrm{i}}$ para cada categoria de veículo. Para se obter o $\mathrm{L}_{\text {Aeq(total) }}$ utiliza-se a Equação 2.

$L_{\text {Aeq }(1, i, i)}=L_{20 s, i}+10 \log \left(\frac{d_{0}}{d}\right)^{\alpha}+10 \log q_{i}-22,553$

Outra formulação baseada no $\mathrm{L}_{20 \mathrm{~s}}$ foi proposta por Zhao et al. (2015), conforme descrito na Equação 10. Sendo $\Delta \phi$ o ângulo, para um observador situado a $15 \mathrm{~m}$ de distância do centro da via, medido em radianos, entre o início e o fim do período de $20 \mathrm{~s}$ de medição. Os valores de $L_{20 s}$ são os fornecidos por Pamanikabud et al. (2008). Para se obter o $\mathrm{L}_{\text {Aeq(total) }}$ utiliza-se a Equação 2. Zhao et al. (2015) também propuseram que fosse feita uma correção em relação à velocidade, para cada categoria de veículo, a qual pode ser obtido em sua publicação.

$$
L_{A e q(1 h, i)}=L_{20 s, z}+10 \log \left(\frac{d_{0}}{d}\right)^{\alpha}+10 \log q_{i}+10 \log \left(\frac{\Delta \phi}{\Pi}\right)-22,55
$$




\section{Método}

Para validação dos algoritmos matemáticos é necessário que se tenha uma base de dados primários capaz de fornecer os resultados do nível de ruído de uma via expressa. Para tal foram realizadas 30 medições do nível de pressão sonora, em horários diferentes, durante três dias, em uma via de tráfego. O local escolhido para as medições era plano e sem ocupação no entorno, de maneira que o ruído captado foi unicamente o gerado pela via de tráfego, e com fluxo de veículos constante. 0 procedimento de medição foi o indicado pela NBR 10151 (ABNT, 2000), parâmetro nacional para esse tipo de análise, sendo utilizado o protetor de vento, equipamento posicionado a 1,20 metro do piso. 0 mesmo foi ajustado na escala de compensação "A" com resposta rápida. A Figura 1 ilustra o local das medições.

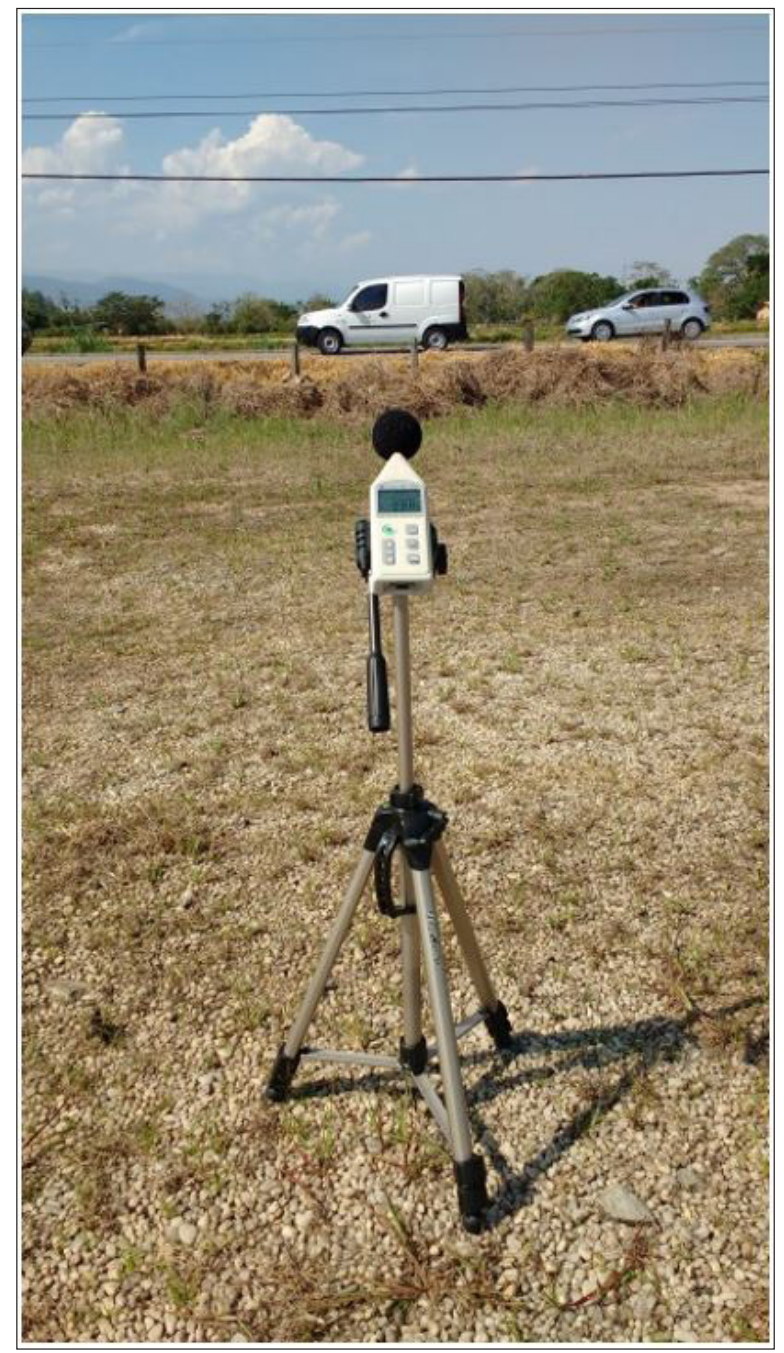

Figura 1 - Vista do medidor de rúío com a via de tráfego ao fundo Fonte: autores.
O tempo de medição na determinação do nível de pressão sonora gerado pelo tráfego é importante devido à variabilidade do fluxo, que gera uma grande alternância de resultados, de maneira que é necessário haver uma base de dados grande o suficiente para que seja calculado o $\mathrm{L}_{\text {Aeq }}$. A agência ambiental do Estado de São Paulo (CETESB) publicou a diretiva DD 100/2009/P, Avaliação de níveis de ruído em sistemas lineares de transporte (CETESB, 2009) que indica o tempo de medição de 10 a 15 minutos para avaliação do ruído de tráfego. Dessa forma, as medições foram conduzidas por um período de 15 minutos cada uma, conforme propõem Romeu et al. (2011). Simultaneamente às medições foram feitas contagens do número de passagens de automóveis, caminhões, ônibus e motocicletas para alimentar os algoritmos. A velocidade considerada na via foi a regulamentada, $60 \mathrm{~km} / \mathrm{h}$. Os resultados foram inseridos nas equações apresentadas para comparação dos resultados.

\section{Resultados e análise}

Os resultados das medições são apresentados na Tabela 1, na qual é possível obter a contagem dos veículos e o nível de pressão sonora obtido. Para o cálculo da porcentagem (\%) de veículos pesados foram considerados os fluxos de ônibus e caminhões.

A Figura 2 apresenta o gráfico com a diferença de resultados (delta) entre o $\mathrm{L}_{\text {Aeq }}$ simulado nos algoritmos por meio das Equações 1 e 2 (FHWA, 1998) e Equações 3 e 4 (HMSO, 1988) e o valor obtido nas medições realizadas. Observa-se que no primeiro modelo os erros ficaram entre $3 \mathrm{~dB}(\mathrm{~A})$ e $8 \mathrm{~dB}(\mathrm{~A})$ e, no segundo modelo, entre $5 \mathrm{~dB}(\mathrm{~A})$ e $8 \mathrm{~dB}(\mathrm{~A})$. Melo et al. (2015) também testaram esse modelo com diferenças entre $-5 \mathrm{~dB}(\mathrm{~A})$ a $2 \mathrm{~dB}(\mathrm{~A})$. 0 modelo da HMSO (1988) não distingue categoria de veículos, apenas veículos leves e pesados. Na simulação, os automóveis e motocicletas foram considerados veículos leves e caminhões e ônibus, veículos pesados. 0 coeficiente $\alpha$, que corresponde à atenuação dada pelo meio entre a fonte o local de análise, nesse caso, posição do receptor, não precisou ser utilizado, pois o medidor estava posicionado a $15 \mathrm{~m}$ do centro da via, que é a distância base do algoritmo. 0 modelo da HMSO (1988) não prevê essa atenuação e, caso necessário, deve ser calculado à parte, conforme indicado na literatura. Importante notar que o 
Tabela 1 - Resultados obtidos nas medições do nível de pressão sonora $\left(\mathrm{L}_{\text {Aeq }}\right)$ e na contagem dos veículos $(\mathrm{v} / \mathrm{h})$

\begin{tabular}{|c|c|c|c|c|c|c|c|}
\hline Medição & $\begin{array}{l}\text { Total de } \\
\text { veículos } \\
\text { (v/h) }\end{array}$ & $\begin{array}{c}\text { Automóveis } \\
\text { (v/h) }\end{array}$ & $\begin{array}{l}\text { Motocicletas } \\
\text { (v/h) }\end{array}$ & $\begin{array}{l}\text { Caminhões } \\
\text { (v/h) }\end{array}$ & $\begin{array}{l}\text { Ônibus } \\
\text { (v/h) }\end{array}$ & $\begin{array}{l}\% \text { de veículos } \\
\text { pesados }\end{array}$ & $\underset{[\mathrm{dB}(A)]}{\mathrm{L}_{\text {eq }}}$ \\
\hline 1 & 504 & 356 & 68 & 76 & 4 & 13,0 & 62,4 \\
\hline 2 & 400 & 312 & 24 & 52 & 12 & 17,5 & 61,2 \\
\hline 3 & 412 & 268 & 64 & 72 & 8 & 18,3 & 60,2 \\
\hline 4 & 372 & 256 & 44 & 68 & 4 & 20,0 & 60,7 \\
\hline 5 & 380 & 268 & 32 & 76 & 4 & 5,6 & 60,7 \\
\hline 6 & 496 & 400 & 56 & 28 & 12 & 16,0 & 61,9 \\
\hline 7 & 476 & 328 & 68 & 76 & 4 & 6,3 & 60,2 \\
\hline 8 & 448 & 332 & 84 & 28 & 4 & 9,0 & 60,2 \\
\hline 9 & 400 & 312 & 44 & 36 & 8 & 5,9 & 60,4 \\
\hline 10 & 476 & 352 & 80 & 28 & 16 & 4,3 & 60,3 \\
\hline 11 & 464 & 364 & 68 & 20 & 12 & 8,7 & 60,7 \\
\hline 12 & 596 & 476 & 56 & 52 & 12 & 9,0 & 62,5 \\
\hline 13 & 624 & 468 & 96 & 56 & 4 & 8,8 & 62,3 \\
\hline 14 & 684 & 480 & 132 & 60 & 12 & 9,3 & 63,5 \\
\hline 15 & 644 & 424 & 148 & 60 & 12 & 5,7 & 61,8 \\
\hline 16 & 696 & 540 & 100 & 40 & 16 & 8,3 & 62,7 \\
\hline 17 & 724 & 516 & 132 & 60 & 16 & 12,6 & 61,0 \\
\hline 18 & 476 & 356 & 48 & 60 & 12 & 9,8 & 61,8 \\
\hline 19 & 488 & 376 & 60 & 48 & 4 & 10,7 & 60,3 \\
\hline 20 & 488 & 372 & 56 & 52 & 8 & 14,9 & 61,1 \\
\hline 21 & 484 & 344 & 56 & 72 & 12 & 5,1 & 60,9 \\
\hline 22 & 396 & 304 & 60 & 20 & 12 & 13,4 & 60,3 \\
\hline 23 & 568 & 424 & 56 & 76 & 12 & 9,6 & 61,0 \\
\hline 24 & 460 & 376 & 36 & 44 & 4 & 8,3 & 61,4 \\
\hline 25 & 576 & 412 & 108 & 48 & 8 & 10,0 & 60,0 \\
\hline 26 & 520 & 376 & 84 & 52 & 8 & 6,4 & 60,8 \\
\hline 27 & 560 & 448 & 64 & 36 & 12 & 15,3 & 60,7 \\
\hline 28 & 524 & 404 & 32 & 80 & 8 & 7,8 & 60,6 \\
\hline 29 & 460 & 380 & 40 & 36 & 4 & 9,6 & 61,5 \\
\hline 30 & 540 & 424 & 60 & 52 & 4 & 13,0 & 61,2 \\
\hline
\end{tabular}

Fonte: autores.

modelo da HMSO (1988) considera uma distância de 13,5 m da lateral da via, enquanto o modelo da FHWA (1998) considera a distância de $15 \mathrm{~m}$ a partir do centro da via. Dessa forma a distância base dos dois algoritmos é a mesma. A grande diferença entre os resultados medidos e o simulado pode ser justificada por serem os modelos já antigos e sem atualização, que simulam o tráfego de veículos mais ruidosos que os atuais.
A Figura 3 apresenta o gráfico com a diferença de resultados (delta) entre o $\mathrm{L}_{\text {Aeq }}$ simulado nos algoritmos e o valor obtido nas medições realizadas. Para a simulação do modelo proposto por Tansatcha et al. (2005) foram utilizadas as Equações 2 e 7, Pamanikabud et al. (2008), Equações 2 e 9, Zhao et al. (2015), Equações 2 e 10. As diferenças de resultados gerados por Tansatcha et al. (2005) foram significativas, praticamente todas acima de $8 \mathrm{~dB}(\mathrm{~A})$. Melo et al. (2015) obtiveram diferenças 


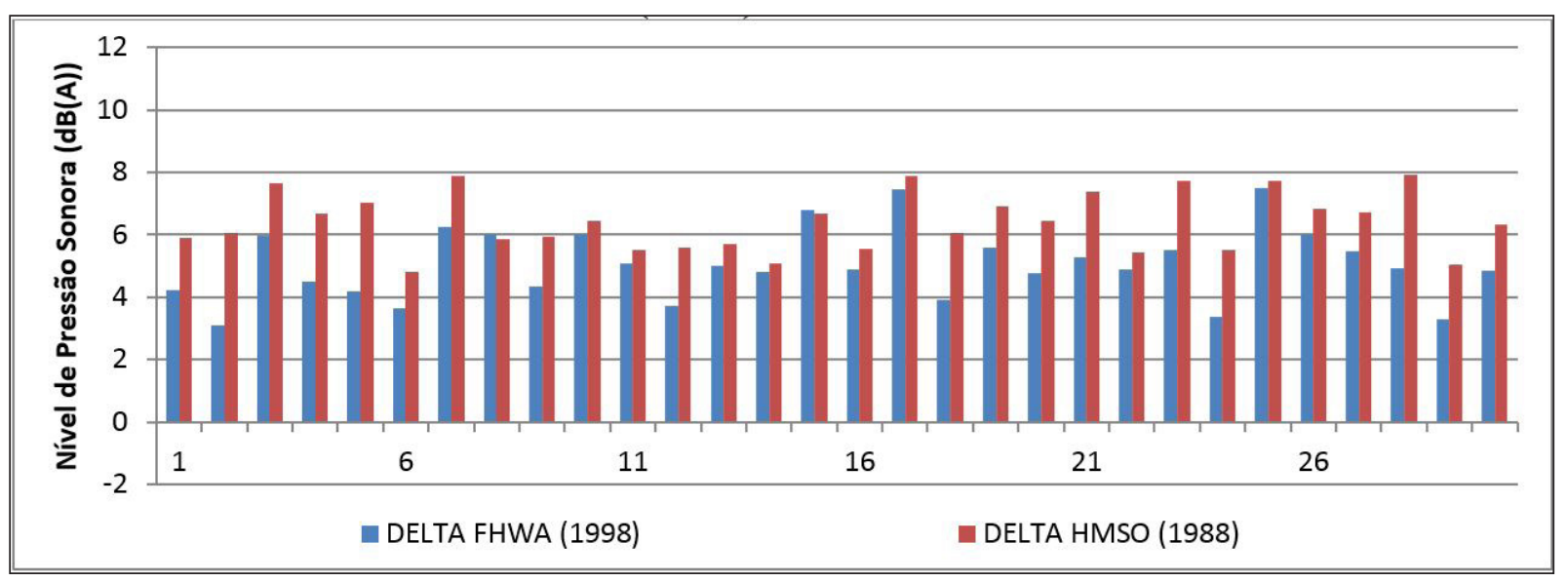

Figura 2 - Gráfico com as diferenças entre o valor simulado pelos algoritmos FHWA (1998) e HMSO (1988) e o valor medido Fonte: autores.

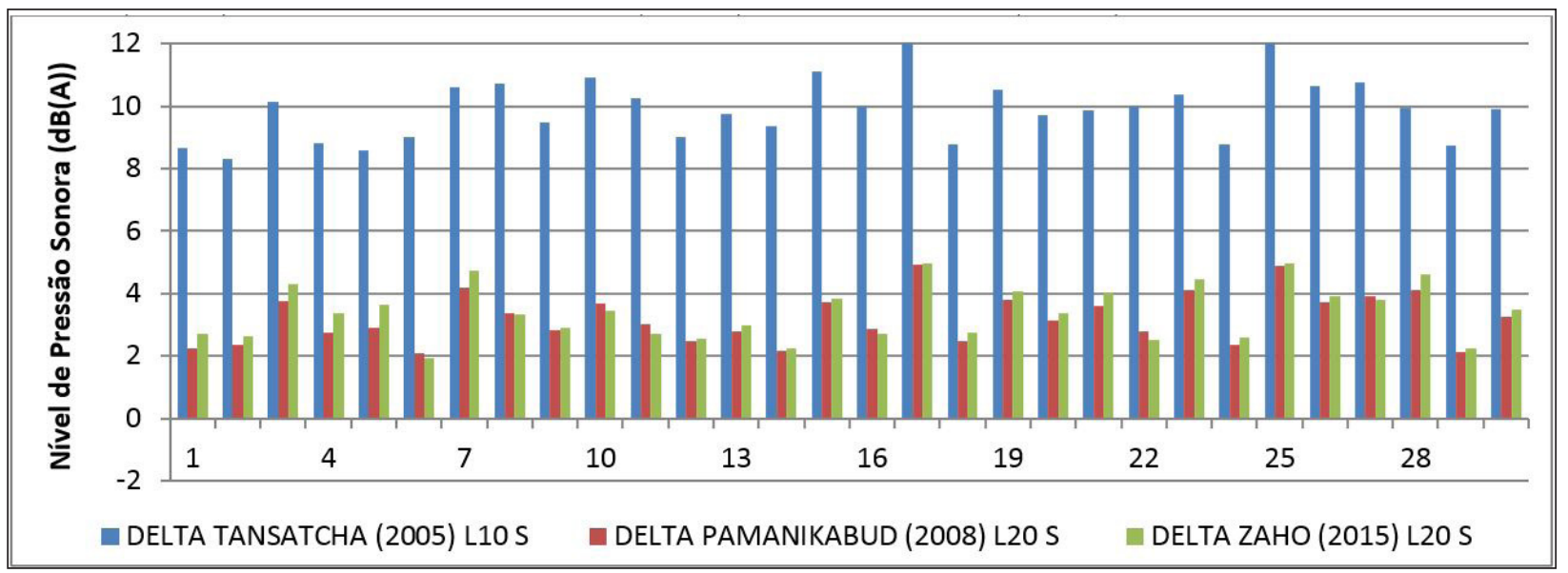

Figura 3 - Gráfico com as diferenças entre o valor simulado pelos algoritmos de Tansatcha et al. (2005), Pamanikabud et al. (2008) e Zhao et al. (2015) e 0 valor medido

Fonte: autores.

similares na aplicação desse modelo com diferenças de $5 \mathrm{~dB}(\mathrm{~A})$ a $7 \mathrm{~dB}(\mathrm{~A})$. Os modelos propostos por Pamanikabud et al. (2008) e Zhao et al. (2015) apresentaram resultados similares, fato já esperado, já que Zhao et al. (2015) utiliza o valor de $\mathrm{L}_{20 \text { s }}$ proposto por Pamanikabud et al. (2008). As diferenças entre o simulado e o medido foram de $2 \mathrm{~dB}(\mathrm{~A})$ e $5 \mathrm{~dB}(\mathrm{~A})$. 0 modelo proposto por Tansatcha et al. (2005), que considera o $\mathrm{L}_{10 \mathrm{~s}}$ como base do algoritmo para uma fonte dipolo, não apresentou resultados satisfatórios. Nos modelos em que a fonte é considerada monopolo (FHWA, 1998; HMSO, 1988), se utiliza o $\mathrm{L}_{55^{\prime}}$ ou seja, o tempo de $10 \mathrm{~s}$ de medição não foi suficiente para caracterização da fonte dipolo, situação conseguida apenas com os modelos de $\mathrm{L}_{20 s^{\prime}}$ como em Pamanikabud et al. (2008) e Zhao et al. (2015).

Uma proposta para melhoria dos resultados simulados com o modelo FHWA (1998) seria utilizar os valores de $\mathrm{L}_{10 \mathrm{~s}}$ de Tansatcha et al. (2005) e $\mathrm{L}_{20 \mathrm{~s}}$ de Pamanikabud et al. (2008) ao invés de utilizar o $L_{5 s}$ proposto em FHWA (1998), como apresentados na Figura 2.0 resultado dessa simulação é apresentado na Figura 4, na qual é possível observar a redução das diferenças entre valor simulado e medido, principalmente quando se utiliza o $\mathrm{L}_{20 \mathrm{~s}}$

Na Tabela 2 são apresentados os valores propostos para $\mathrm{L}_{5 \mathrm{~s}}$ (FHWA, 1998), $\mathrm{L}_{10 \mathrm{~s}}$ (Tansatcha et al., 2005) e $\mathrm{L}_{20 \mathrm{~s}}$ (Pamanikabud et al., 2008) que foram inseridos nos algoritmos, considerando-se a velocidade de $60 \mathrm{~km} / \mathrm{h}$ 


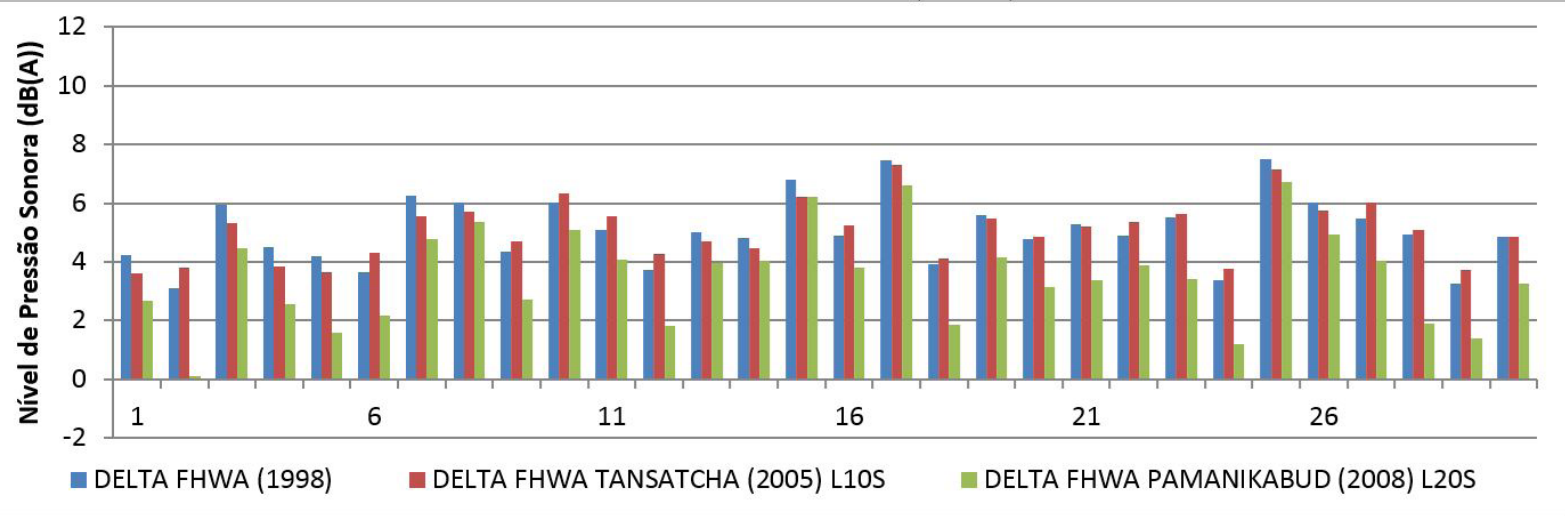

Figura 4 - Gráfico com as diferenças entre o valor simulado pelos algoritmos propostos por FHWA (1998), FHWA (1998) utilizando $0 \mathrm{~L}_{10 \mathrm{~s}}$ de Tansatcha et al. (2005) e FHWA (1998) utilizando o $L_{20 s}$ de Pamanikabud et al. (2008) e o valor medido Fonte: autores.

Tabela 2 - Valores obtidos de $L_{55^{\prime}} L_{10 s}$ e $L_{20 s}$ para as simulações em dB(A), considerando uma velocidade de $60 \mathrm{~km} / \mathrm{h}$

\begin{tabular}{lcccc}
\hline & Automóveis & Motocicletas & Caminhões & Ônibus \\
\hline FHWA (1998) $\mathrm{L}_{55}$ & 65,0 & 76,0 & 73,0 & 73,0 \\
Tansatcha et al. (2005) $\mathrm{L}_{10} \mathrm{~S}$ & 68,3 & 73,9 & 67,4 & 73,1 \\
Pamanikabud et al. (2008) $\mathrm{L}_{20 \mathrm{~s}}$ & 58,7 & 60,5 & 66,1 & 68,4 \\
\hline
\end{tabular}

Fonte: autores.

utilizada neste trabalho. É possível observar a diversidade de resultados, em alguns casos bastante significativa, como no das motocicletas, que variam até $16 \mathrm{~dB}(\mathrm{~A})$, diferença entre $\mathrm{o} \mathrm{L}_{5 \mathrm{~s}}$ e o $\mathrm{L}_{20 \mathrm{~s}}$ e outros inesperados, como o caso do $\mathrm{L}_{10 \mathrm{~s}}$ para caminhões ser menor que para automóveis.

As adaptações propostas por Lam \& Tam (1998) e Tang \& Tong (2004) no algoritmo proposto por HMSO (1988) são apresentadas na Figura 5, na qual é possível observar a significativa redução da diferença entre o valor simulado e o medido. 0 modelo proposto por Lam \& Tam (1998) apresentou diferenças entre $1 \mathrm{~dB}(\mathrm{~A})$ e $4 \mathrm{~dB}(\mathrm{~A})$, sendo mais da metade das diferenças inferiores a $2 \mathrm{~dB}(\mathrm{~A})$, e o modelo proposto por Tang \& Tong (2004) apresentou diferenças entre $2 \mathrm{~dB}(\mathrm{~A})$ e $5 \mathrm{~dB}(\mathrm{~A})$. 0 modelo proposto por Tang \& Tong (2004) possui também a ferramenta para avaliação de vias em aclive, não disponível nos demais modelos.

De uma forma geral, todos os algoritmos testados apresentaram diferenças positivas. Essas diferenças podem ser justificadas pelos modelos serem, de certa forma, antigos, sendo que o mais novo, Zhao et al. (2015), utiliza o $\mathrm{L}_{20 \mathrm{~s}}$ de Pamanikabud et al.
(2008), de maneira que isso influi no resultado final. A idade do modelo pode também representar uma realidade passada, típica da época da obtenção do $\mathrm{L}_{5 s^{\prime}} \mathrm{L}_{10 \mathrm{~s}}$ e $\mathrm{L}_{20 \mathrm{~s}}$. Ao mesmo tempo, o fato de a diferença entre o simulado e o medido ser positiva favorece $o$ processo de planejamento urbano, já que a paisagem sonora prevista será superior à real.

As medições de nível de ruído realizadas para validação dos modelos apresentaram uma diferença de cerca de 3,3 $\mathrm{dB}(\mathrm{A})$ entre o menor valor [60,2 $\mathrm{dB}(\mathrm{A})]$ e o maior [63,5 $\mathrm{dB}(\mathrm{A})]$, ocasionada pela variação do volume de tráfego. Os modelos que consideram a fonte de ruído como monopolo (FHWA, 1998; HMSO, 1988) apresentaram diferenças consideravelmente superiores às obtidas nas medições [3,3 $\mathrm{dB}(\mathrm{A})]$, que pode ser tomada como uma referência de precisão de resultados. A substituição do $\mathrm{L}_{5 \mathrm{~s}}$ no modelo da FHWA (1998) pelo $\mathrm{L}_{10 \mathrm{~s}}$ de Tansatcha et al. (2005) não foi satisfatória, havendo uma melhora na precisão somente quando da substituição do $\mathrm{L}_{5 \mathrm{~s}}$ pelo $L_{20 s}$ de Pamanikabud et al. (2008), mas ainda sendo superior à referência adotada. A adaptação do algoritmo da HMSO (1988) proposta por Lam \& Tam (1998) apresentou diferenças abaixo de 3,3 dB(A) 


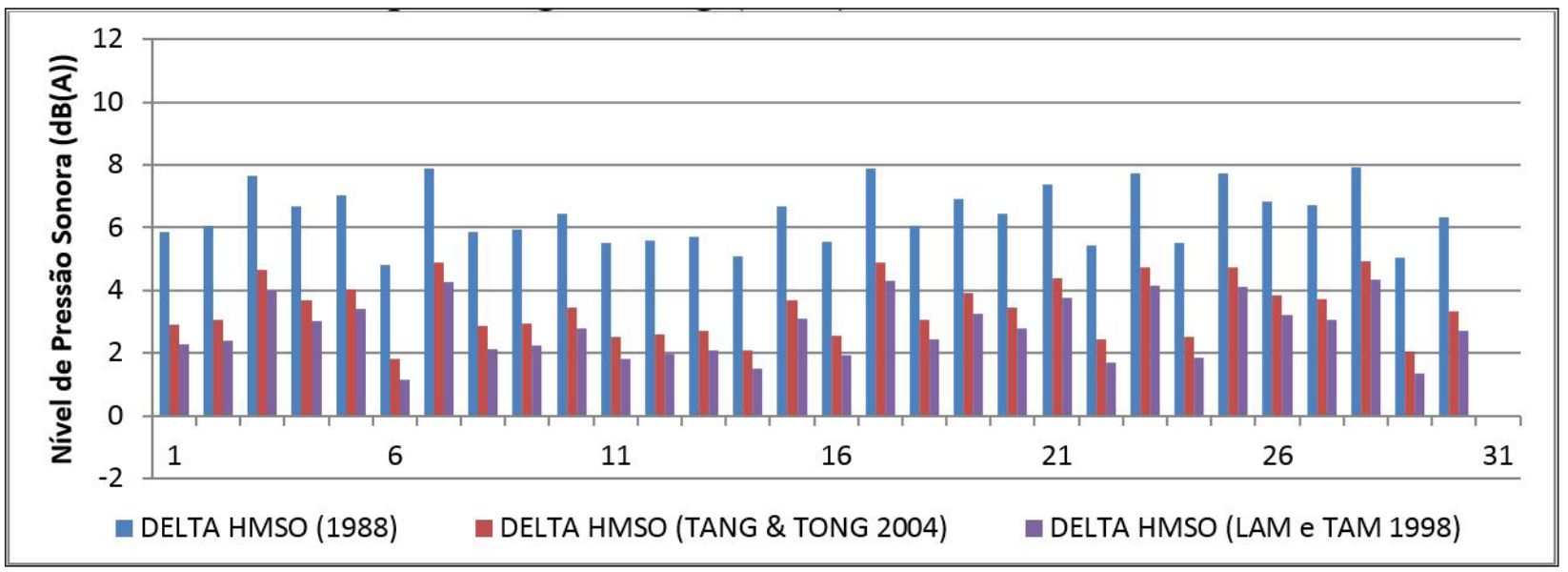

Figura 5 - Gráfico com as diferenças entre o valor simulado pelos algoritmos propostos por HMSO (1988), HMSO (1988) adaptado por Lam \& Tam (1998) e HMSO (1988) adaptado por Tang \& Tong (2004) e o valor medido

Fonte: autores.

em 24 das 30 simulações realizadas, tento uma boa correspondência com as medições.

Dentre os modelos que consideram a fonte dipolo, o proposto por Tansatcha et al. (2005) não se mostrou adequado devido a elevada diferença entre o simulado e o medido. 0 modelo proposto por Pamanikabud et al. (2008) gerou 12 resultados superiores a 3,3 $\mathrm{dB}(\mathrm{A})$ de diferença e o proposto por Zhao et al. (2015), 16 resultados, de maneira que a confiabilidade da simulação (cerca de 50\%) não é satisfatória.

Os algoritmos da FHWA (1998) e da HMSO (1988) não citam o tipo de pavimento considerado na formulação nem propõem algum tipo de correção e, como visto na revisão da literatura, podem elevar ou reduzir a emissão de energia sonora. Lam \& Tam (1998) propuseram uma correção de $-1 \mathrm{~dB}(\mathrm{~A})$ no modelo que desenvolveram quando o pavimento for asfáltico betuminoso, o que ajudou a melhorar a precisão nos resultados. Os algoritmos que utilizam $\mathrm{L}_{5 s^{\prime}}, \mathrm{L}_{10 \mathrm{~s}}$ e $\mathrm{L}_{20 \mathrm{~s}}$ não informam em qual situação e tipo de pavimento foram obtidos, fato que certamente reduz a precisão dos resultados.

A velocidade utilizada na simulação foi a regulamentada pela sinalização, $60 \mathrm{~km} / \mathrm{h}$, de maneira que alguns veículos podem ter passado pelo medidor acima dela e outros abaixo, assim, na média, considera-se que a velocidade utilizada na simulação foi a realmente existente na via.

A via avaliada, uma rodovia de acesso a uma cidade, possui um volume de média intensidade, entre $400 \mathrm{v} / \mathrm{h}$ e $750 \mathrm{v} / \mathrm{h}$, nela os veículos trafegam em média a velocidade de $60 \mathrm{~km} / \mathrm{h}$, em um pavimento de boas condições, podendo ser comparada a grandes avenidas de tráfego contínuo, ou rodovias que se tornam avenidas, comuns em cidades de médio e grande porte. Essa é uma situação recorrente, como já observado por Calixto et al. (2003). Nas medições realizadas, a energia sonora obtida foi superior a $60 \mathrm{~dB}(\mathrm{~A})$ a $15 \mathrm{~m}$ de distância da via, superando em $5 \mathrm{~dB}(\mathrm{~A})$ o critério para áreas de ocupação mista e em $10 \mathrm{~dB}(\mathrm{~A})$ o critério de áreas de ocupação residencial, de acordo com a NBR 10151 (2000). A energia sonora decai cerca de $3 \mathrm{~dB}(\mathrm{~A})$ para cada vez que se dobra a distância, considerando as avenidas longas e de tráfego contínuo. A dedução matemática de tal afirmação pode ser conseguida em Gerges (2002) ou Bistafa (2006). Dessa forma, o critério de $55 \mathrm{~dB}(\mathrm{~A})$ é atendido apenas a 60 $\mathrm{m}$ da via e o critério de $50 \mathrm{~dB}(\mathrm{~A})$, a mais de $120 \mathrm{~m}$ de distância. Essa hipótese considera o campo aberto, já que demanda recuos impensáveis de serem adotados no meio urbano, mas que podem ser conseguidos com a utilização de outros equipamentos urbanos como praças e jardins, quando propostos no planejamento das cidades, demostrando assim a importância da simulação da emissão de ruído nesse processo.

\section{Conclusões}

Para que a paisagem sonora do meio urbano seja controlada é necessário que o planejamento considere a energia sonora emitida por vias de tráfego e faça uso 
de meios de controle para sua redução e sua dispersão. Equipamentos urbanos como praças, jardins, parques lineares, taludes naturais, entre outros, podem ser úteis nessa tarefa.

A utilização de algoritmos matemáticos para a previsão do ruído gerado por uma via de tráfego é uma ferramenta útil ao planejamento urbano. Softwares comerciais de alto custo monopolizaram esse tipo de estudo e acabaram inibindo a atualização de algoritmos livres disponíveis na literatura. Os algoritmos utilizados nos softwares não são abertos, de maneira que não é possível adaptá-los à realidade nacional.

O modelo proposto por Lam \& Tam (1998) foi o que melhor apresentou correlação de dados entre os valores medidos e simulados, sendo também o único que sugere uma correção para tipo de pavimento.

Para uma melhor adaptação dos algoritmos à realidade nacional é necessário criar um banco de dados de valores de $\mathrm{L}_{20 \mathrm{~s}}$ para diferentes tipos de pavimentos. Esse banco pode alimentar os algoritmos de FHWA (1998), Pamanikabud et al. (2008) e Zhao et al. (2015), para nova verificação da precisão de resultados.

\section{Referências}

Aleixo, P., Constantino, M., \& Carvalho, M. L. U. (2014). Análise da paisagem sonora das praças: Cívica e Tamandaré em Goiânia-GO, Brasil. In Anais do XXV Encontro da Sociedade Brasileira de Acústica (pp. 238-245). Campinas: SOBRAC.

Alexandre, A., \& Barde, J. (1975). Road traffic noise. London: Apllied Science Plublishers.

Ariza-Villaverde, A. B., Jiménez-Hornero, F. J., \& Gutiérrez De Ravé, E. (2014). Influence of urban morphology on total noise pollution: Multifractal description. The Science of the Total Environment, 472, 1-8. PMid:24286721. http:// dx.doi.org/10.1016/j.scitotenv.2013.10.091.

Associação Brasileira de Normas Técnicas - ABNT. (2000). NBR 10151: acústica - avaliação do ruído em áreas habitadas, visando o conforto da comunidade. Rio de Janeiro: ABNT.

Belojević, G. A., Jakovljevic, B. D., Stojanov, V. J., Slepcevic, V. Z., \& Paunovic, K. Z. (2008). Nighttime road-traffic noise and arterial hypertension in an urban population. Hypertension Research, 31(4), 775-781. PMid:18633190. http://dx.doi.org/10.1291/hypres.31.775.

Bistafa, S. (2006). Acústica aplicada ao controle de ruído. São Paulo: Edgard Blucher.
Brito, L. A. P. F. (2009). Metodologia para estimativa do ruído de tráfego: aspectos práticos e de precisão. In Anais do X Encontro Nacional Sobre o Conforto no Ambiente Construído. Natal: ANTAC.

Brito, L. A. P. F. (2014). Avaliação do tráfego rodoviário como fonte de vibração e incômodo no meio urbano. In Anais do XXV Encontro da Sociedade Brasileira de Acústica. Campinas: SOBRAC.

Brito, L. A. P. F., \& Barbosa, A. S. (2014). Incremento do nível de ruído no meio urbano devido às atividades turísticas: estudo de caso na cidade de Campos do Jordão. Revista Tecno-Lógica, 18(2), 84-89.

Calixto, A., Diniz, F. B., \& Zannin, P. H. T. (2003). The statistical modeling of road traffic noise in an urban setting. Cities (London, England), 20(1), 23-29. http://dx.doi.org/10.1016/ S0264-2751(02)00093-8.

Companhia de Tecnologia de Saneamento Ambiental CETESB. (2009). Decisão de diretoria n- 100/2009/P, de 19 de maio de 2009. Dispõe sobre a aprovação do procedimento para avaliação de níveis de ruído em sistemas lineares de transporte. São Paulo: CETESB.

Eisenblaetter, J., Walsh, S. J., \& Krylov, V. V. (2010). Airrelated mechanisms of noise generation by solid rubber tyres with cavities. Applied Acoustics, 71(9), 854-860. http://dx.doi.org/10.1016/j.apacoust.2010.05.002.

Estévez, L., García, E., Cepeda, J., Búrdalo, G., Barios, M., \& Barrios, M. (2013). Acoustic characterization of pedestrian areas. In Proceedings of The Internoise 2013 - noise control for quality life. Innsbruck: INCE.

Federal Highway Administration - FHWA. (1998). Traffic noise model, technical manual. Washington: FWHA.

Forum of European National Highway Research Laboratories - FEHRL. (2006). Guidance manual for the implementation of low-noise road surfaces (v. 2). Belgium: FEHRL.

Gerges, S. (2002). Ruídos, fundamentos e controle (2. ed.). Florianópolis: NR Editora.

Giunta, M. B., Souza, L. C. L., \& Viviani, E. (2012). Ruído ambiental em cidades de médio porte: estudo dos casos das cidades de São Carlos e Bauru - SP. In Anais do XXIV Encontro da Sociedade Brasileira de Acústica. Belém: SOBRAC.

Golebiewski, R., Makarewicz, R., Nowak, M., \& Preis, A. (2003). Traffic noise reduction due to the porous road surface. Applied Acoustics, 64(5), 481-494. http://dx.doi. org/10.1016/S0003-682X(02)00124-X. 
Guedes, I. C. M., Kohler, R., \& Carvalho, R. M. (2014). Estudo de impacto do ruído de tráfego veicular Aracaju (SE) Brasil. In Anais do XXV Encontro da Sociedade Brasileira de Acústica (p. 26-33). Campinas: SOBRAC.

Heckl, M. (1985). Tyre noise generation. In Proceedings of The Seminar of Friction and Contact Noise. Delft: Delft University of Technology.

Her Majesty's Stationery Office, Department of Transport - HMSO. (1988). Calculation of road traffic noise. London: HMSO.

Ivanovic, L., Josifovic, D., Ili, A., Stojanovic, B., \& Rakic, B. (2014). Noise as aspect of life quality at urban areas. In 8th International Quality Conference. Kragujevac: University of Kragujevac.

Klæboe, R., Amundsen, A. H., Fyhri, A., \& Solberg, S. (2004). Road traffic noise - the relationship between noise exposure and noise annoyance in Norway. Applied Acoustics, 65(9), 893-912. http://dx.doi.org/10.1016/j.apacoust.2004.04.001.

Lam, H. K., \& Tam, M. L. (1998). Reliability analysis of traffic noise estimates in Hong Kong. Transportation Research, 3(4), 238-248.

Łowicki, D., \& Piotrowska, S. (2015). Monetary valuation of road noise. Residential property prices as an indicator of the acoustic climate quality. Ecological Indicators, 52, 472-479. http://dx.doi.org/10.1016/j.ecolind.2015.01.002.

Melo, R. A., Pimentel, R. L., Lacerda, D. M., \& Silva, W. M. (2015). Applicability of models to estimate traffic noise for urban roads. Journal of Environmental Health Science \& Engineering, 13(1), 83. PMid:26634126. http://dx.doi. org/10.1186/s40201-015-0240-9.

Musafir, R. E. (2008). Uma discussão sobre a NBR 10.151 (avaliação de ruído em áreas habitadas visando o conforto da comunidade) In Anais do XXII Encontro da Sociedade Brasileira de Acústica. Belo Horizonte: SOBRAC.

Niemeyer, M. L., \& Cortês, M. (2012). Avaliação do incômodo sonoro da linha vermelha no bairro de São Cristóvão, Rio de Janeiro. In Anais do Encontro da Sociedade Brasileira de Acústica. Belém: SOBRAC.

Paje, S. E., Bueno, M., Terán, F., Miró, R., Pérez-Jiménez, F., \& Martínez, A. H. (2010). Acoustic field evaluation of asphalt mixtures with crumb rubber. Applied Acoustics, 71(6), 578582. http://dx.doi.org/10.1016/j.apacoust.2009.12.003.

Pamanikabud, P., Tansatcha, M., \& Brown, A. L. (2008). Development of a highway noise prediction model using an $\mathrm{L}_{\mathrm{eq}} 20 \mathrm{~s}$ measure of basic vehicular noise. Journal of Sound and Vibration, 316(1-5), 317-330. http://dx.doi. org/10.1016/j.jsv.2008.02.054.

Pirrera, S., Valck, E., \& Cluydts, R. (2014). Field study on the impact of nocturnal road traffic noise on sleep: the importance of in- and outdoor noise assessment, the bedroom location and nighttime noise disturbances. The Science of the Total Environment, 500-501, 84-90. PMid:25217747. http://dx.doi.org/10.1016/j.scitotenv.2014.08.061.

Romeu, J., Genescà, M., Pàmies, T., \& Jiménez, S. (2011). Street categorization for the estimation of day levels using short-term measurements. Applied Acoustics, 72(8), 569577. http://dx.doi.org/10.1016/j.apacoust.2010.09.012.

Salomons, E. M., \& Pont, M. B. (2012). Urban traffic noise and the relation to urban density, form, and traffic elasticity. Landscape and Urban Planning, 108(1), 2-16. http://dx.doi. org/10.1016/j.landurbplan.2012.06.017.

Scherer, M. J., Piageti, G., \& Vani, L. (2008). 0 ruído urbano e a desvalorização imobiliária. In Anais do XXII Encontro da Sociedade Brasileira de Acústica. Belo Horizonte: SOBRAC.

Schimitt, N. I. M. (2014). Avaliação do ruído ambiental em Porto Alegre - RS. In Anais do XXV Encontro da Sociedade Brasileira de Acústica (p. 42-50). Campinas: SOBRAC.

Silva, L. T., Oliveira, M., \& Silva, J. F. (2014). Urban form indicators as proxy on the noise exposure of buildings. Applied Acoustics, 76, 366-376. http://dx.doi.org/10.1016/j. apacoust.2013.07.027.

Steele, C. (2001). A critical review of some traffic noise prediction models. Applied Acoustics, 62(3), 271-287. http:// dx.doi.org/10.1016/S0003-682X(00)00030-X.

Szczepanska, A., Senetra, A., \& Wasilewicz-Pszczołkowska, M. (2015). The effect of road traffic noise on the prices of residential property - a case study of the polish city of Olsztyn. Transportation Research, 36, 167-177.

Szeremeta, B., \& Zannin, P. H. T. (2009). Analysis and evaluation of soundscapes in public parks through interviews and measurement of noise. The Science of the Total Environment, 407(24), 6143-6149. PMid:19786294. http://dx.doi.org/10.1016/j.scitotenv.2009.08.039.

Tang, S. K., \& Tong, K. K. (2004). Estimating traffic noise for inclined roads with freely flowing traffic. Applied Acoustics, 65(2), 171-181. http://dx.doi.org/10.1016/j. apacoust.2003.08.001. 
Tansatcha, M., Pamanikabud, P., Brown, A. L., \& Affum, J. K. (2005). Motorway noise modeling based on perpendicular propagation analysis of traffic noise. Applied Acoustics, 66(10), 1135-1150. http://dx.doi.org/10.1016/j. apacoust.2005.02.002.

Tsai, K.-T., Lin, M.-D., \& Chen, Y.-H. (2009). Noise mapping in urban environments: a Taiwan study. Applied Acoustics, 70(7), 964-972. http://dx.doi.org/10.1016/j.apacoust.2008.11.001.

Weber, N., Haase, D., \& Franck, U. (2014). Assessing modeled outdoor traffic-induced noise and air pollution around urban structures using the concept of landscape metrics.
Landscape and Urban Planning, 125, 105-116. http:// dx.doi.org/10.1016/j.landurbplan.2014.02.018.

World Health Organization - WHO. (2009). Night noise guidelines for Europe. Copenhagen: WHO Regional Office.

Zhao, J., Ding, Z., Hu, B., Chen, Y., \& Yang, W. (2015). Assessment and improvement of a highway traffic noise prediction model with $\mathrm{L}_{\text {eq }}(20 \mathrm{~s})$ as the basic vehicular noise. Applied Acoustics, 97, 78-83. http://dx.doi.org/10.1016/j. apacoust.2015.03.021.

Recebido: Fev. 23, 2016

Aprovado: Dez. 13, 2016 